\title{
In vitro effect of a mucolytic thiol agent on the activity of polymorphonuclear leucocyte elastase and antileucoprotease
}

\author{
J STOLK, J A KRAMPS, J H DIJKMAN \\ From the Department of Pulmonology, University Hospital, Leiden, The Netherlands
}

ABSTRACT We have studied the effects of the mucolytic thiol agent mercapto-ethanesulphonate (mesna) on the activity of both polymorphonuclear leucocyte (PMN) elastase and antileucoprotease $\circ$ in vitro. In all tests a specific synthetic substrate was used to measure elastase activity, which was then related to enzyme activity in the absence of mesna. The relative elastase activity decreased to $z$ $67.5 \%$ of control values after the enzyme had been incubated in a $120 \mathrm{mmol} / \mathrm{l}$ mesna solution. In the sol phase of purulent sputum, elastase activity decreased to $45 \%$ after the sol phase had been $\stackrel{\$}{3}$ incubated in a $600 \mathrm{mmol} / \mathrm{l}$ mesna solution. The inability to reverse the inhibition of mesna by increasing the substrate concentration indicated that mesna acts as a non-competitive inhibitor of $\vec{\theta}$ PMN elastase. Incubation of elastase with antileucoprotease reduced the relative elastase activity ${ }_{\infty}^{\infty}$ to $21 \%$. When antileucoprotease was preincubated in a $60 \mathrm{mmol} / 1 \mathrm{mesna}$ solution under identical assay conditions, a relative elastase activity of $39 \%$ was observed. Inhibition experiments with mesna treated antileucoprotease, in which sulphydryl groups were blocked with iodoacetamide, strongly suggested that the dissociation constant $\left(\mathrm{K}_{\mathbf{i}}\right)$ of the fraction of antileucoprotease that retains activity after the incubation with mesna was not changed. Elastase inhibitory activity in mucoid sol $\odot$ phase, which can be ascribed mainly to antileucoprotease, decreased to $53 \%$ after incubation with $\overrightarrow{\overrightarrow{0}}$ mesna at a concentration of $960 \mathrm{mmol} / 1$. Incubation of PMN elastase/antileucoprotease complex 3 with mesna did not result in any release of active PMN elastase from the antileucoprotease. It is concluded that mesna and other thiol compounds, when locally administered, may influence the proteinase-antiproteinase balance in the airways by their effect on both PMN elastase and antileucoprotease.

The current theory of the pathogenesis of emphysema is that the destruction of lung elastin might be the result of a disequilibrium of the normal proteinaseantiproteinase balance within the lung, in which proteinase activity is in excess. ${ }^{12}$ This idea has evolved from the clinical experience with patients who have $\alpha_{1}$ proteinase inhibitor deficiency. These patients have decreased serum $\alpha_{1}$ proteinase inhibitor activity and develop panacinar emphysema during early adult life. A similar imbalance is created when increased numbers of polymorphonuclear leucocytes (PMN) are attracted to the lung, either by bacterial infection or by cigarette smoke. ${ }^{3}$ In addition, the destructive effect of PMN elastase on lung tissue might play a part in

Address for reprint requests: Dr J A Kramps, Department of Pul-
monology (C3-P), University Hospital, Rijnsburgerweg 10, 2333 AA
Leiden, The Netherlands.

Accepted 27 May 1986 the adult respiratory distress syndrome, ${ }^{4}$ and its $\frac{0}{3}$ adverse effects on the mucociliary activity of respiratory epithelium may be important in patients with $\frac{\mathrm{O}}{3}$

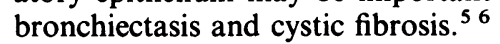

Antileucoprotease and $\alpha_{1}$ proteinase inhibitor are $\stackrel{\circ}{\supset}$ the major proteinase inhibitors in the respiratory $\frac{?}{0}$ tract. $^{7}$ Alpha ${ }_{1}$ proteinase inhibitor is derived from serum and mainly produced by the liver, ${ }^{8}$ whereas $N$ antileucoprotease was found to be produced by the serous secretory cells of the submucosal glands ${ }^{9}$ and $\mathrm{N}$ by non-ciliated cells of the bronchiolar epithelium. ${ }^{10} \mathrm{~W}$ Alpha $_{1}$ proteinase inhibitor is a more important? inhibitor than antileucoprotease in peripheral air-을 ways, ${ }^{1112}$ whereas in bronchial fluids Tegner $^{7}$ estimated that about $90 \%$ of the PMN elastase inhibition ${ }^{+}$ is caused by antileucoprotease.

Thiol compounds, which can be locally adminis- $\frac{\vec{O}}{\mathbb{D}}$ tered by nebulisers and are capable of reducing S-S $\stackrel{\odot}{\overparen{Q}}$ bonds in mucoproteins to free sulphydryl groups, are $\mathcal{Q}$ 
often used as mucolytic drugs. This study was designed to measure in vitro the effect of a thiol agent on the activity of both PMN elastase and antileucoprotease.

\section{Methods}

EFFECT OF THIOL AGENT ON PMN ELASTASE ACTIVITY

Crude PMN extracts were prepared by sonication of $1.7 \times 10^{6}$ polymorphonuclear leucocytes isolated from peripheral blood, in $1 \mathrm{ml}$ tris $/ \mathrm{NaCl}$ buffer $(0.1 \mathrm{~mol} / 1$ tris; $0.96 \mathrm{~mol} / 1 \mathrm{NaCl} ; \mathrm{pH} 8.3)$. Elastase activity in this extract was measured by using the specific substrate L-pyroglutamyl-L-prolyl-L-valine$p$-nitroanilide (Kabi Diagnostica, Stockholm). ${ }^{13}$ In brief, $200 \mu$ l crude PMN extract was added to $200 \mu \mathrm{l}$ tris/ $\mathrm{NaCl}$ buffer containing $0.1 \%$ gelatin. After incubation of the mixture for 10 minutes at $37^{\circ} \mathrm{C}, 200 \mu \mathrm{l}$ substrate was added. Absorbance increase during the first three minutes was measured at $405 \mathrm{~nm}$ in a photometer with cuvette housing maintained at $37^{\circ} \mathrm{C}$.

To measure the effect of the thiol agent on elastase activity, $200 \mu$ l buffer was replaced by $200 \mu$ l thiol agent in the same buffer. After an incubation of 10 minutes at $37^{\circ} \mathrm{C}$ the substrate was added to measure the elastase activity, which was then related to the enzyme activity in the absence of thiol agent. Mercapto-ethanesulphonate (mesna, Mistabron, UCB, Brussels) solutions were added to the PMN extracts at concentrations ranging from 6 to $240 \mathrm{mmol} / \mathrm{l}$.

To verify the possibility of a direct effect of mesna on the assay system (for example, a direct effect of mesna on the substrate), substrate was incubated with buffer containing increasing amounts of mesna for 10 minutes at $37^{\circ} \mathrm{C}$. Then an extract of polymorphonuclear leucocytes was added and the absorbance increase was measured immediately. No effect of mesna on the absorbance increase was observed when the measurements were performed during the first 15 seconds.

To investigate the type of inhibition of elastase by mesna, enzyme activities in the absence and in the presence of mesna were measured at final substrate concentrations ranging from 0.05 to $0.67 \mathrm{mmol} / \mathrm{l}$. Double reciprocal regression plots were constructed from these data.

EFFECT OF THIOL AGENT ON ANTILEUCOPROTEASE ACTIVITY

Antileucoprotease, purified by a method previously described, ${ }^{14}$ was dissolved in tris/ $\mathrm{NaCl}$ buffer at a concentration of $1.9 \mu \mathrm{g} / \mathrm{ml}$ and preincubated with the thiol agent for $\mathbf{3 0}$ minutes at room temperature. Thiol agent concentrations in the antileucoprotease solution ranged from 7.5 to $60 \mathrm{mmol} / \mathrm{l}$. Then $200 \mu \mathrm{l}$ of preincubated antileucoprotease was incubated with $200 \mu \mathrm{l} \mathrm{PMN}$ extract for 10 minutes at $37^{\circ} \mathrm{C}$ in a cuvette and substrate was added to measure absorbance increase during the first 3 minutes. Residual enzyme activity was compared with a blank of enzyme, buffer, and substrate alone and expressed as percentage (relative elastase activity).

In another experiment $43 \mu \mathrm{g}$ antileucoprotease was incubated for 30 minutes at room temperature in $400 \mu \mathrm{l}$ buffer containing mesna at a concentration of $300 \mathrm{mmol} / \mathrm{l}$. To block free sulphydryl groups in the antileucoprotease molecule, which might be formed during the incubation with mesna, and to block the sulphydryl groups of mesna, which was present in excess in the reaction mixture, $500 \mu \mathrm{l}$ of $300 \mathrm{mmol} / \mathrm{l}$ iodoacetamide in tris/ $\mathrm{NaCl}(\mathrm{pH} 8.0)$ buffer was added and allowed to react for one hour at room temperature. Then the mixture was serially diluted in buffer and elastase inhibitory activity was measured as described with the use of PMN extract. As a control experiment, $43 \mu \mathrm{g}$ antileucoprotease was incubated in $400 \mu \mathrm{l}$ buffer without mesna. The subsequent steps, including the addition of iodoacetamide, were performed as described above.

\section{EFFECT OF THIOL AGENT ON}

ELASTASE-ANTILEUCOPROTEASE COMPLEX

Elastase-antileucoprotease complex, which was prepared by incubating $200 \mu \mathrm{l}$ PMN extract with $200 \mu \mathrm{l}$ antileucoprotease solution $(1.3 \mu \mathrm{g} / \mathrm{ml})$ for 30 minutes at room temperature, was treated with $200 \mu$ mesna solution $(60 \mathrm{mmol} / \mathrm{l})$. After an incubation period of 10 minutes at $37^{\circ} \mathrm{C} 200 \mu \mathrm{l}$ substrate was added and the absorbance increase at $405 \mathrm{~nm}$ was measured. The experiment was repeated by using antileucoprotease in excess $(38 \mu \mathrm{g} / \mathrm{ml})$, which was shown to inactivate the elastase activity completely.

EFFECT OF THIOL AGENT ON ELASTASE ACTIVITY AND ANTILEUCOPROTEASE ACTIVITY IN SPUTUM Samples of green purulent and mucoid sputum were sonicated three times at $30 \mathrm{~W}$ for 30 seconds at $0^{\circ} \mathrm{C}$ with a Branson B-12 sonifier and centrifuged for 5 minutes at $8500 \mathrm{~g}$. The resulting purulent sol phase was diluted 10 times with tris/ $\mathrm{NaCl}$ buffer. Elastase activity in $200 \mu$ of this diluted sol phase was measured as described above; there was a change in absorbance similar to that of the crude PMN extract prepared as described. The effect of thiol agent on the elastase activity in the purulent sol phase was determined by preincubation of $200 \mu$ l diluted sol phase with $200 \mu \mathrm{l}$ mesna solution (final concentration ranging from $30 \mathrm{mmol} / 1$ to $600 \mathrm{mmol} / \mathrm{l}$ ) for 10 minutes at $37^{\circ} \mathrm{C}$.

To $50 \mu \mathrm{l}$ mucoid sol phase containing elastase 
inhibitor activity $450 \mu \mathrm{l}$ buffer or mesna solution was added (final mesna concentration $50-960 \mathrm{mmol} / \mathrm{l}$ ) and incubated for 30 minutes at room temperature. Then the mixture was diluted six times and to $200 \mu$ lof this $200 \mu \mathrm{l}$ PMN extract was added (final mesna concentration ranged from 4 to $80 \mathrm{mmol} / \mathrm{l})$. After 10 minutes at $37^{\circ} \mathrm{C}$ substrate was added and absorbance increase was measured. To measure the direct effect of mesna on elastase activity, control experiments were run simultaneously in which antileucoprotease was omitted and PMN extracts were incubated with mesna at concentrations ranging from 4 to $80 \mathrm{mmol} / \mathrm{l}$. After a 10 minute incubation at $37^{\circ} \mathrm{C}$ substrate was added.

The reproducibility of the assay system as used in this investigation was determined by measuring the effect of thiol agent on antileucoprotease activity on five consecutive days. The inter assay coefficient of variation was found to be $5 \cdot 9 \%$.

\section{Results}

\section{EFFECT OF THIOL AGENT ON PMN ELASTASE}

\section{ACTIVITY}

The PMN extract showed a mean absorbance increase of about $0 \cdot 300 / \mathrm{min}$ under the conditions described. Incubation of the PMN extract with mesna at a final concentration of $120 \mathrm{mmol} / 1$ resulted in an elastase $\stackrel{\vec{F}}{\stackrel{7}{9}}$ activity that was $67.5 \%$ of the elastase activity in the absence of mesna. The inactivation of the elastase activity was proportional to the mesna concentration (fig $1 a$ ).

The effect of mesna on the elastase activity was also determined at different substrate concentrations. From the data obtained from this series of experiments, double reciprocal (Lineweaver-Burk) plots were constructed. These plots (fig $1 b$ ) differ in slope $\stackrel{\sigma}{\omega}$ and share a common intercept on the $x$-axis $(=\overrightarrow{\vec{x}}$ $\left.-1 / K_{M}\right)$. Thus inhibition by mesna does not have any influence on the Michaelis constant $\left(\mathrm{K}_{\mathrm{M}}\right)$. The inter- cept on the $y$ axis $(1 / v)$ is greater for the inhibited than $\overrightarrow{-}$ for the uninhibited enzyme, indicating that the inhibition by mesna cannot be restored by high substrate concentration.

EFFECT OF THIOL AGENT ON ANTILEUCOPROTEASE ACTIVITY

Incubation of elastase with antileucoprotease in the absence of mesna resulted in a relative elastase activity of $21 \%$. Preincubation of antileucoprotease with a $60 \mathrm{mmol} / 1$ mesna solution (final concentration of $30 \mathrm{mmol} / 1$ in the antileucoprotease enzyme mixture), resulted in a relative elastase activity of $39 \%$. The

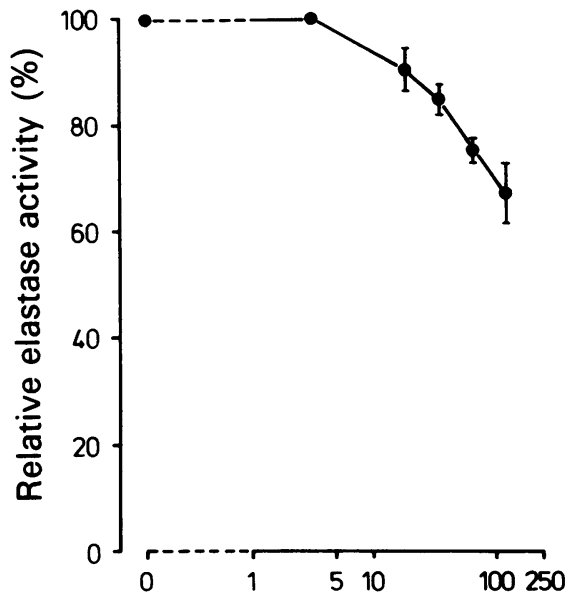

Mercapto-ethanesulphonate

(a)

$$
(\mathrm{mmol} / \mathrm{I})
$$

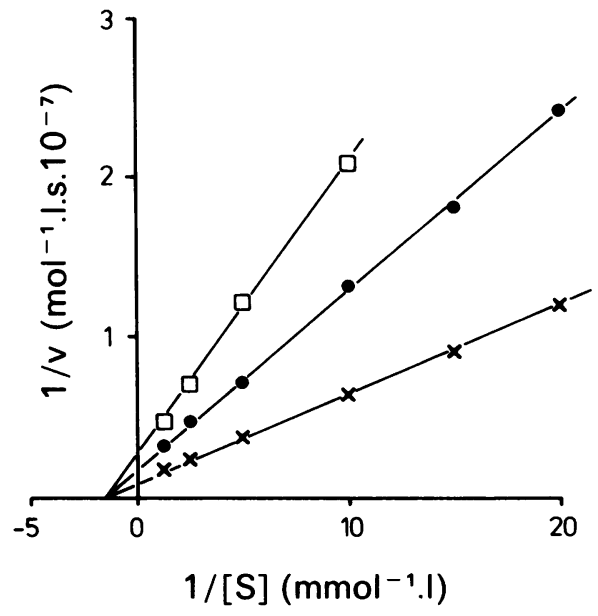

(b)

Fig 1 (a) Inactivation of the elastase activity in a PMN extract by mercapto-ethanesulphonate (mesna) (one volume buffer containing mesna mixed with one volume of PMN extract-final mesna concentrations indicated). After incubation for 10 minutes at $37^{\circ} \mathrm{C}$, substrate was added, and elastase activity, measured by the absorbance increase at $405 \mathrm{~nm}$, was expressed as the percentage of activity in the absence of mesna (means with $S D, n=3$ ). (b) Double reciprocal (Lineweaver-Burk) plots of PMN elastase incubated in buffer containing mesna at concentrations of $0 \mathrm{mmol} / \mathrm{l}(\times-\times), 120 \mathrm{mmol} / \mathrm{l}(\bigcirc-\bigcirc)$, and $300 \mathrm{mmol} / \mathrm{l}(\square-\square)$. For calculation of the initial rate of the enzymatic reaction, a molar extinction coefficient of $9600 \mathrm{~mol}^{-1} \mathrm{l} \mathrm{cm}^{-1}$ for p-nitroaniline was used. 


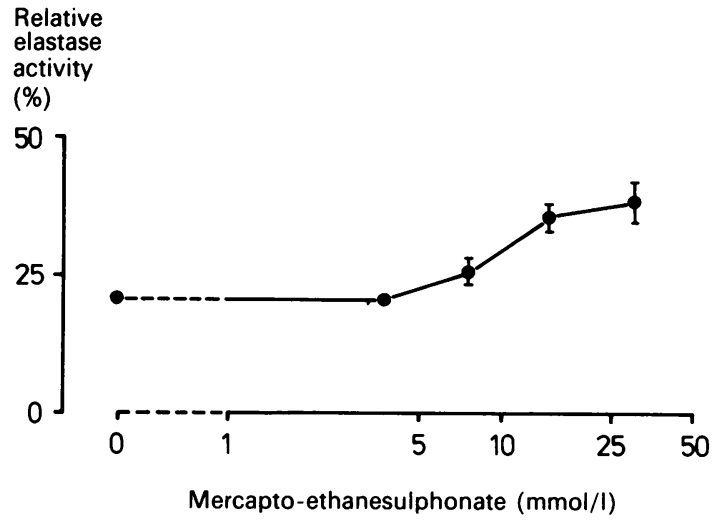

Fig 2 Inactivation by mercapto-ethanesulphonate (mesna) of the inhibition activity of antileucoprotease (ALP) $(1.9 \mathrm{\mu g} / \mathrm{ml}$ ALP incubated for 30 minutes at room temperature in a buffer with mesna, then mixed with an equal volume of polymorphonuclear leucocyte extract-final mesna concentrations indicated). After 10 minutes at $37^{\circ} \mathrm{C}$, elastase activity was measured by adding substrate and related to enzyme activity in the absence of ALP and mesna (means with $S D, n=3$ ). The data reflecting the decrease in ALP activity were not corrected for the inactivation of elastase by the direct effect of mesna on this enzyme during the 10 minutes' incubation at $37^{\circ} \mathrm{C}$. As can be seen in figure 1 , at a mesna concentration of $30 \mathrm{mmol} / \mathrm{l}$ elastase inactivation by mesna was $15 \%$.

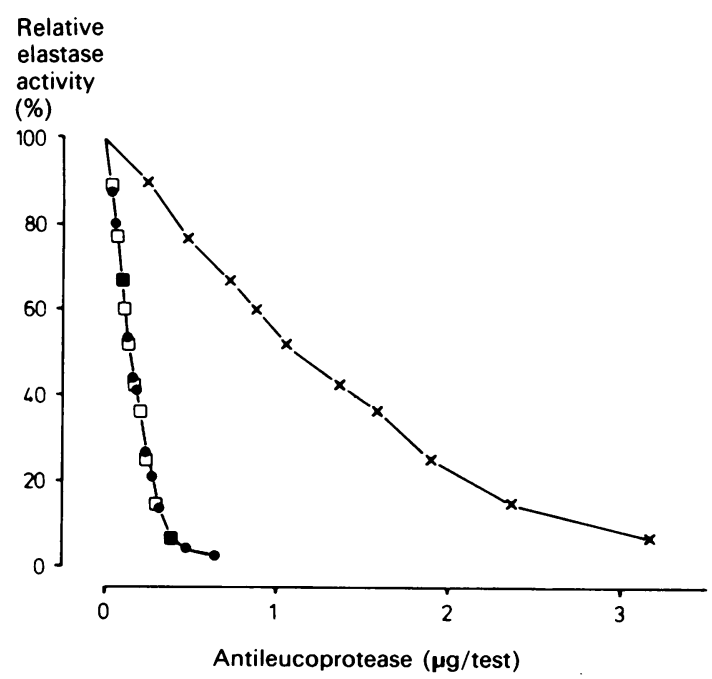

Fig 3 Inhibition experiments with antileucoprotease (ALP) incubated with buffer (containing $300 \mathrm{mmol} / \mathrm{l}$ mesna $(\times-\times)$, and then treated with iodoacetamide. A corrected curve $(\square-\square)$ was calculated from the data obtained with mesna treated $A L P(\times-\times)$ by taking into account the portion of $A L P$ that was inactivated by mesna. increase in elastase activity produced by preincubating the antileucoprotease with mesna was proportional to the final mesna concentrations in the range $4-30 \mathrm{mmol} / \mathrm{l}$ (fig 2 ).

To prevent reoxidation of the free sulphydryl groups formed in the antileucoprotease molecule by mesna, to disulphide, and to prevent inactivation of elastase by the excess of mesna after the addition of the antileucoprotease-mesna mixture to PMN extract in the inhibition assay, an experiment was performed in which the free sulphydryl groups in the antileucoprotease-mesna mixture were blocked by alkylation with iodoacetamide. Then elastase inhibitory activity of the mixture was measured by incubating serial dilutions with PMN extract, after which the remaining elastase activity was measured by adding substrate (fig 3 ). The amount of inhibitor required to block the elastase activity completely can be deduced by extrapolations from the inhibition curves shown in figure 3 . After reduction in a buffer containing $300 \mathrm{mmol} / \mathrm{l}$ mesna and blocking by iodoacetamide, $2 \cdot 20 \mu \mathrm{g}$ antileucoprotease per test was able to completely inhibit the PMN elastase activity. On the other hand, complete inhibition of elastase in the control experiment was obtained with only $0.27 \mu \mathrm{g}$ antileucoprotease per test. Thus in this experiment reduction of antileucoprotease by mesna resulted in $88 \%$ inactivation of the elastase inhibitory activity.

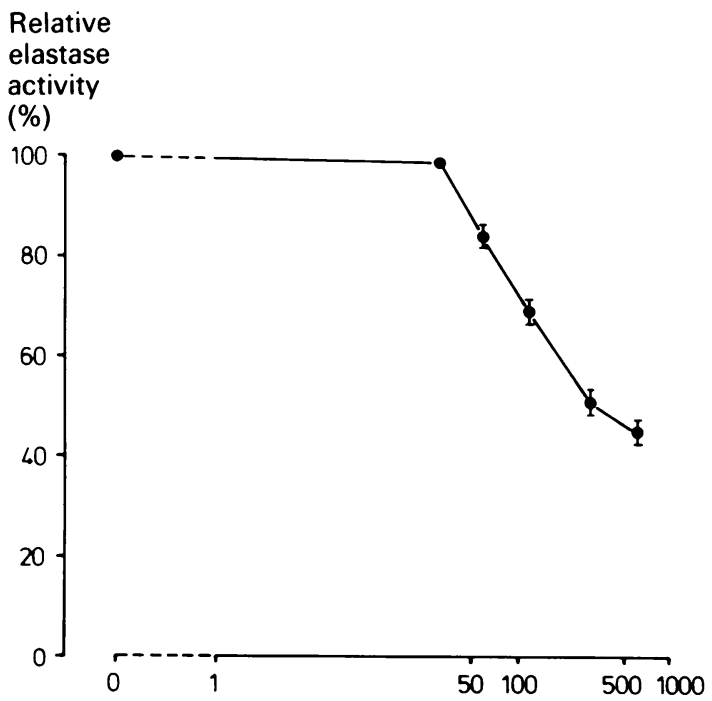

Mercapto-ethanesulphonate ( $\mathrm{mmol} / \mathrm{I})$

Fig 4 Inactivation by mercapto-ethanesulphonate (mesna) of the elastase activity in purulent sputum sol phase (diluted 10 times before being mixed with an equal volume of mesna solution - final mesna concentrations indicated; means with $S D, n=3$ ). For test conditions see figure la. 
EFFECT OF THIOL AGENT ON

PROTEASE-ANTILEUCOPROTEASE COMPLEX

Addition of antileucoprotease $(1 \cdot 3 \mu \mathrm{g} / \mathrm{ml})$ to the crude PMN extract resulted in a relative elastase activity of $17 \%$ under the test conditions described. Incubation of this mixture with mesna (final concentration $20 \mathrm{mmol} / \mathrm{l}$ ) resulted in a $15 \%$ relative elastase activity. When the same amount of antileucoprotease was preincubated with mesna before being mixed with PMN elastase, however, the remaining relative enzyme activity was found to be $32 \%$. PMN elastase preincubated with antileucoprotease in excess and incubated with mesna afterwards did not show detectable enzyme activity.

EFFECTS OF THIOL AGENT ON SPUTUM SOL PHASE Elastase activity in the purulent sol phase diluted 1:10 showed a mean absorbance increase of $0.260 / \mathrm{min}$. Incubation of this mixture with mesna instead of

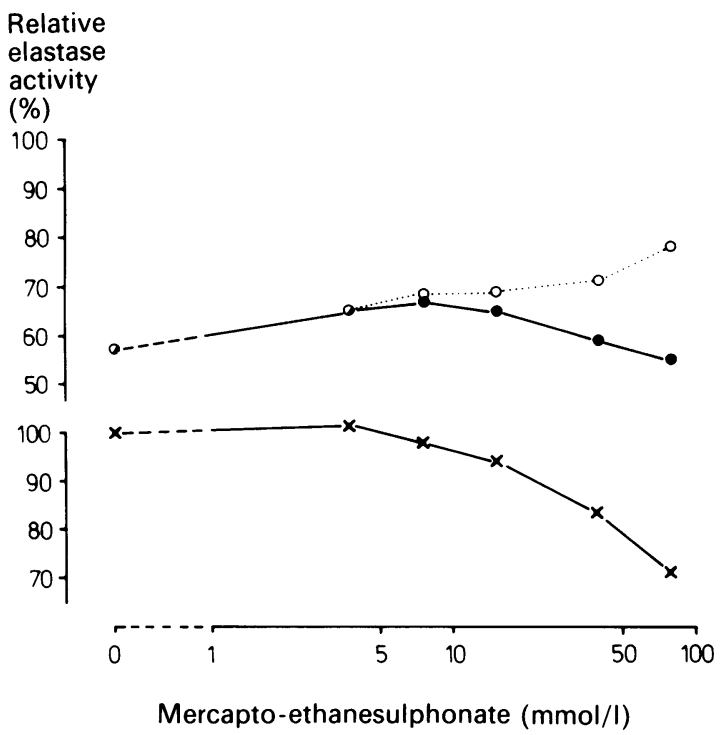

Fig 5 Inactivation of the elastase inhibition activity in mucoid sputum sol phase (diluted 10 times with mercapto-ethanesulphonate (mesna) solution and incubated for 30 minutes at room temperature, then mixture diluted six times and mixed with equal volume of polymorphonuclear leucocyte (PMN) extract-final mesna concentrations are as indicated). After 10 minutes at $37^{\circ} \mathrm{C}$ elastase activity was measured by adding substrate

(- To depict the effect of mesna on the elastase inhibition activity alone, data were corrected for the direct effect of mesna on the elastase activity: the elastase activity in the presence of mucoid sol phase, as measured at a given mesna concentration, was corrected for the percentage inactivation of elastase by mesna $(\bigcirc \ldots . . . . . .$.$) on the basis$ of the results obtained by incubating PMN extract with mesna alone $(\times-\times)$. buffer reduced the elastase activity in proportion to $\overrightarrow{\overrightarrow{\mathrm{D}}}$ the mesna concentration (see fig 4).

The effect of mesna on the elastase inhibitor activity of mucoid sputum sol phase is shown in figure 5. The $\frac{}{\bar{m}}$ dotted line has been obtained by correction of the uninhibited elastase activity for the direct effect of mesna on this enzyme. Calculations from these cor- $\infty$ rected data show that the highest mesna concentration $\vec{\circ}$ used in this experiment resulted in an inhibitor activity that is only $53 \%$ of the inhibitor activity in the absence of mesna.

\section{Discussion}

Thiol compounds, such as dithiothreitol and glutathione, are able to inactivate enzymes by reducing S-S bonds to free sulphydryl groups. ${ }^{15}$ Recently 옥 Biondy et $\mathrm{l}^{16}$ used dithiothreitol to inactivate bovine trypsin inhibitor. In the present study the direct effects of a mucolytic thiol agent on the activity of PMN elastase, antileucoprotease, and their complex were studied. Effects of thiol on the activity of these com- $\stackrel{\mathbb{D}}{-}$ pounds might have implications for the proteinase- $\overrightarrow{0}$ antiproteinase balance within the lung. The inactivation of human PMN elastase and of antileucoprotease by mesna in vitro are the most important aspects of this study and suggest that disulphide bonds within the molecules are important for their integrity. Amino acid analysis has shown that $\stackrel{\circ}{\mathbb{D}}$ purified PMN elastase contains about 6 and anti- $\Omega$ leucoprotease $10-14$ half cystine residues..$^{91417}$ In $\overrightarrow{\vec{O}}$ recent experiments we have found that anti- $\exists$ leucoprotease contains six disulphide bridges (unpublished result). Clearly mesna, which is a reducing agent by virtue of its sulphydryl group, is able to inactivate PMN elastase and antileucoprotease by splitting intrachain S-S bonds to form free sulphydryl $\underset{x}{x}$ groups.

It can be deduced from the Lineweaver-Burk plots shown in figure $1 b$ that inhibition of elastase by mesna does not change the Michaelis constant. Moreover, inhibition by mesna cannot be reversed by increasing 9 the substrate concentration. These results strongly $D$ suggest that mesna is a non-competitive inhibitor of PMN elastase, which is consistent with the data show- N ing that mesna inactivates PMN elastase by splitting disulphide bonds.

Mesna also effects the activity of antileucoprotease $N^{\omega}$ (figs 2 and 3). From the inhibition curves shown in figure 3 it was calculated that an incubation witho $300 \mathrm{mmol} / 1 \mathrm{mesna}$ resulted in $88 \%$ inactivation of the $\mathbb{\varnothing}$ antileucoprotease activity. When corrections were $\stackrel{\mathcal{f}}{+}$ made for the amount of antileucoprotease inactivated $\underset{T}{T}$ by mesna, an inhibition curve was obtained that was $\frac{?}{\mathbb{D}}$ superimposed on the curve obtained with anti- $\stackrel{\Omega}{\Omega}$ leucoprotease not incubated with mesna (fig 3). This $\stackrel{\mathbb{Q}}{\mathbb{Q}}$ 
observation indicates that the dissociation constant $\left(\mathrm{K}_{\mathrm{i}}\right)$ of the active fraction of antileucoprotease, as estimated from the inhibition curve, ${ }^{18}$ is not changed during the incubation with mesna.

Incubation of the elastase-antileucoprotease complex with mesna did not result in any release of elastolytic activity from the complex, suggesting that the complex is stable in the presence of mesna.

We thought that cystine containing mucoproteins, which are present in large amounts in sputum sol phase, might protect PMN elastase and antileucoprotease against inactivation by thiol agents. We found, however, that mesna was very effective in the inactivation of PMN elastase and antileucoprotease when these proteins are present in purulent and mucoid sputum sol phase respectively (figs 4 and 5).

In experiments not presented here we found that the qualitative effects of the thiol agent acetyl cysteine on the activity of PMN elastase and antileucoprotease were similar to the effects of mesna (unpublished results).

From the results of this investigation, we conclude that administration of mucolytic thiol compounds by nebulisers might cause a reduction of free elastase activity or of free elastase inhibition activity in sputum. Stockley et $a l^{19}$ reported a positive correlation between the PMN elastase activity in sputum and its purulence. Since PMN elastase is thought to be of major importance in destructive lung disease, decreasing the elastase load as much as possible seems rational. Thus, besides acting as mucolytic drugs, thiol compounds might protect the lung against proteolytic damage by inactivating part of the PMN elastase activity in patients producing purulent sputum. Administration of thiol compounds in patients producing mucoid sputum might, however, result in inactivation of antileucoprotease, which is the major elastase inhibitor in sputum. A more extensive investigation in patients producing sputum is needed to gain more knowledge about the in vivo effect of thiol compounds on the elastase activity and the elastase inhibitor activity in sputum.

We would like to thank Drs E C Klasen and P Niermeyer for critically reviewing this work, Mrs Ch van Twisk for her skilled technical assistance, and Mrs E A van der Kwast for typing the manuscript.

\section{References}

1 Hance AJ, Crystal RG. The connective tissue of the lung. Am Rev Respir Dis 1976;112:657-711.

2 Cohen AB. Proteases and antiproteases in the lung. Am Rev Respir Dis 1983;127:S2-S58.
3 Janoff A. Biochemical links between cigarette smoke and pulmonary emphysema. J Appl Physiol 1983;55: 285-93.

4 Tate A, Pepine C. Neutrophils and the adult respiratory distress syndrome. Am Rev Respir Dis 1983;128:552-9.

5 Tegner H, Ohlson K, Toremalm NG, von Mecklenburg C. Effect of human leukocyte enzymes on tracheal mucosa and its mucociliary activity. Rhinology 1979;17:199-206.

6 Smallman LA, Hill SL, Stockley RA. Reduction of ciliary beat frequency in vitro by sputum from patients with bronchiectasis: a serine proteinase effect. Thorax 1984;39:663-7.

7 Tegner H. Quantitation of human granulocyte protease inhibitors in non-purulent bronchial lavage fluids. Acta Otolaryngol 1978;85:282-6.

8 Gautier M, Martin JP, Polini G. In vitro synthesis of alpha ${ }_{1}$-antitrypsin in long term monolayer of human cell cultures. Biomedicine 1977;27:116-9.

9 Kramps JA, Franken C, Meyer CJLM, Dijkman JH. Localization of low molecular weight protease inhibitor in serous secretory cells of the respiratory tract. $J$ Histochem Cytochem 1981;29:712-9.

10 Water de R, Willems LNA, Muijen van GNP, Franken C, Fransen JAM, Dijkman JH, Kramps JA. Ultrastructural localization of bronchial antileukoprotease in central and peripheral human airways by a goldlabeling technique using monoclonal antibodies. $\mathrm{Am}$ Rev Respir Dis 1986;133:882-90.

11 Gadek JE, Fells GA, Zimmerman RL, Rennard SI, Crystal RG. Anti-elastase of human alveolar structure. $J$ Clin Invest 1981;68:889-98.

12 Kramps JA, Franken C, Dijkman JH. Low-molecularweight protease inhibitor in the peripheral lung [abstract]. Respiration 1984;46 (suppl 1):156.

13 Kramps JA, van Twisk Ch, van der Linden A. L-pyroglutamyl-L-prolyl-L-valine-p-nitroanilide, a highly specific substrate for granulocyte elastase. Scand J Clin Lab Invest 1983;43:427-32.

14 Ohlsson K, Tegner H, Akesson U. Isolation and partial characterization of a low-molecular-weight-acid stable-protease inhibitor from human bronchial secretions. Hoppe Seyler's Z Physiol Chem 1977;358:583-9.

15 Teschsche H, Haenisch G. Regeneration of native structure and biological activity by air oxidation of reduced pancreatic secretory trypsin inhibitor. FEBS Lett 1970;11:209-12.

16 Biondy L, Rocchi R. Regeneration of native structure and biological activity by air oxidation of reduced bovine trypsin inhibitor. Int $J$ Peptide Protein Res 1984:24:359-61.

17 Twumasi DY, Liener IE. Proteases from purulent sputum. J Biol Chem 1977;252:1917-26.

18 Green NM, Work E. Pancreatic trypsin inhibitor. 2. Reaction with trypsin. Biochem $J$ 1953;54:347-52.

19 Stockley RA, Hill SL, Morrison HM, Starkie CM. Elastolytic activity of sputum and its relation to purulence and lung function in patients with bronchiectasis. Thorax 1984;39:401-7. 